Hispania, 2014, vol. LXXIV, nº. 247, mayo-agosto, págs. 411-438

ISSN: 0018-2141, e-ISSN: 1988-8368, doi: 10.3989/hispania.2014.013

\title{
El proyecto general para las fortificaciones de Alicante en $1721^{*}$
}

\section{Víctor Echarri Iribarren}

Universidad de Alicante

RESUMEN: El auge de la actividad portuaria en Alicante, y los acontecimientos bélicos que sufrió la ciudad durante la Guerra de Sucesión, despertaron el interés por modernizar su obsoleto recinto amurallado. Este artículo describe el proyecto general de 1721 para las fortificaciones de esta ciudad - hasta la fecha desconocido-y valora su calidad técnica. Fue sin duda el mejor proyecto que se realizó para la modernización de las fortificaciones de Alicante durante el siglo XVIII. No tenemos noticia de la memoria que debió de elaborarse, pero sí un plano de 1721 que se conserva en el Servicio Geográfico del Ejército, hasta el momento considerado anónimo. El hecho de que el Ingeniero General Jorge Próspero de Verboom visitara Alicante en esa fecha, además de otras valoraciones técnicas, permite atribuir su autoría a dicho ingeniero. Se describen también otros proyectos coetáneos de ingenieros militares elaborados por orden de Verboom.

\section{PAlabras Clave: Verboom; fortificaciones; ingenieros militares; Ali- cante; cartografía antigua; siglo XVIII.}

\section{The General Project for the Fortifications of Alicante in 1721}

ABSTRACT: The boom in activity at the Port of Alicante and events in the city during the War of Succession sparked interest in modernising its obsolete walled enclosure. This article describes the general project for the city's fortifi-

* Este trabajo se ha realizado en el marco del proyecto de investigación sobre el castillo y las fortificaciones de Alicante financiado por la Generalitat Valenciana (ref. GV07/150), la Fundación Manuel Peláez y del Vicerrectorado de investigación de la Universidad de Alicante (ref. ACIE11-02). Las abreviaturas utilizadas son: AGS (Archivo General de Simancas); ACA (Archivo de la Corona de Aragón); SGE (Servicio Geográfico del Ejército); IHCM (Instituto de Historia y Cultura Militar); BL (British Library); BNE (Biblioteca Nacional de España); AMA (Archivo Municipal de Alicante); SHD (Service Historique de la Défense). 
cations from 1721, which until now remained unknown, and assesses its technical quality. It was undoubtedly the finest project of those undertaken in the 18th century to modernise Alicante's fortifications. No record exists of the report that must have been produced, but there is a surviving map from 1721 kept at the Army's Geographic Service that until recently had been considered anonymous. The fact that General Engineer Jorge Próspero de Verboom visited Alicante at this time, together with other technical considerations, means the report can be attributed to him. Other contemporary projects by military engineers produced by order of Verboom are also described.

KEY WORDS: Verboom; Fortifications; Military engineers; Alicante; Old maps; Eighteenth century.

\section{ANTECEDENTES HISTÓRICOS}

Alicante fue desde antiguo un estratégico enclave defensivo de carácter natural, propiciado por la singular elevación del monte Benacantil sobre su puerto. Bajo la dominación musulmana se construyó un inexpugnable castillo en su cima. La pequeña población situada en las faldas de dicha montaña experimentó una importante transformación, siendo circundada por un recinto amurallado $^{1}$. Tras la reconquista cristiana en el siglo XII, dichas murallas sufrieron a su vez diversas modificaciones, adquiriendo una estructura a base de torres cuadrangulares típicamente medieval.

Tras el desarrollo del poder ofensivo de la artillería y la aparición de los primeros baluartes a comienzos del siglo XVI, Carlos V ordenó a sus ingenieros que trazasen un nuevo recinto, capaz de alojar artillería en sus anchas torres circulares ${ }^{2}$. El nuevo recinto contó con cinco baluartes redondos: de la Ampolla, San Francisco, Monserrate, San Bartolomé y San Sebastián. Fue una de las primeras ciudades en contar con un recinto a la moderna, prueba de la importancia estratégica de nuestra ciudad ante la amenaza turca.

Pronto el recinto quedó obsoleto ante el avance técnico y destructor que experimentaron las piezas de artillería. Al igual que sucediera en otras plazas, Felipe II decidió modernizar las fortificaciones de Alicante con bastiones de última generación, es decir, con ángulo de flanqueo y casamatas. Para ello

1 Cfr. BEVIÀ I GARCÍA, 1, (Alicante, 1984): 131-140. ROSSER LIMIÑANA, 1990.

2 La fisonomía del recinto se reproduce con exactitud en el conocido cuadro titulado "El embarque de los moriscos en el puerto de Alicante", en el que se representa la expulsión de los moriscos en 1609. También en otra representación menos fiel de 1689, de G. Gentile, en que «el diseño de los edificios y la geometrización del recinto sugieren que el autor no ha visitado nunca la ciudad». ROSELLÓ VERGER, 2008: 263. 
envió a sus mejores ingenieros - Juan Bautista Antonelli ${ }^{3}$ en primera instancia y Jacobo Palear Fratín en segunda- quienes hicieron reconocimientos y elaboraron proyectos. El proyecto del primero era muy ambicioso y difícilmente financiable ${ }^{4}$. El Fratín, denominado «mi yngeniero» por Felipe II $^{5}$, se centró exclusivamente en reforzar las defensas del castillo. Proyectó un frente bastionado en su zona más baja, en el alcázar viejo, que a través de casamatas y troneras, evitaba un fácil acceso al enemigo ${ }^{6}$.

Las actuaciones en las fortificaciones de Alicante durante el siglo XVII estuvieron condicionadas por la política exterior de la Monarquía española. Mantener la supremacía en el escenario internacional conllevaba un importante esfuerzo bélico. Una vez disipada la amenaza turca, las fricciones en los Países Bajos, Portugal, y otros territorios de la Corona desviaron la actividad defensiva hacia los espacios de frontera en Europa - especialmente con Francia - y Colonias de ultramar. Alicante fue considerada a comienzos de siglo una plaza de segundo orden dentro del marco estratégico de la defensa peninsular. Así lo refleja un informe de Tiburcio Spannocchi, Ingeniero Mayor encargado de la superintendencia de las fortificaciones españolas ${ }^{7}$. Pero dicha valoración se vio modificada conforme su puerto creció en actividad económica. Así Juan Bautista Paravesino, síndico de la ciudad, trazó un plan en $1656^{8}$ para poder sufragar los costes de una nueva fortificación ${ }^{9}$, y a finales de siglo se redactaron ambiciosos proyectos para una plaza convertida en puerta del Levante hacia el interior peninsular.

3 Cfr. GONZÁLEZ AVILÉS, 3532, (Madrid, 2012).

4 Carta del Fratín al virrey Marqués de Mondéjar de fecha 20 de diciembre de 1574, AGS, Guerra y Marina, legajo. 78, $\mathrm{n}^{\circ} 36$.

5 Cfr. VIGANÒ, 2004.

6 Carta de D. Pedro de Velasco al Marqués de Mondéjar de 21 de diciembre de 1574, AGS, Guerra y Marina, legajo 78, $\mathrm{n}^{\mathrm{o}} 33$.

7 Este experto ingeniero, en informe de 16 de febrero de 1605, resaltaba la necesidad de ir fortificando paulatinamente la península. Proponía comenzar por lo indispensable, que eran las fortalezas a las que denominaba «llaves de España»: Fuenterrabía y San Sebastián, La Coruña, la Barra de Lisboa, el Castillo de Cádiz, Gibraltar, Cartagena, el Castillo de Perpignan, el Castillo de Jaca y el Castillo de Pamplona. AGS, Guerra y Marina, legajo 929.

8 En el ACA ha quedado un plano que en los últimos años había sido erróneamente atribuido a él como autor, y de fecha también errónea de 1656. Recientes investigaciones han demostrado que dicho plano va adjunto al expediente del memorial de Joseph de Borja de fecha 1693. ACA. MP. No 77. Cfr. ECHARRI, 7/23, (Madrid, 2011).

9 La situación de las fortificaciones de la Corona de Aragón, y en especial del reino de Valencia, era de absoluta ineficacia en la segunda mitad del siglo XVII. La labor de redacción de proyectos de fortificación se veía interrumpida en cuanto a su ejecución por la escasez de fondos, con un continuo tira y afloja entre el Consell y la Corona. Cfr. ESPINO LÓPEZ, 2007: 154-55. 
Desde los orígenes de la fortificación abaluartada los ingenieros del Renacimiento habían debatido ampliamente sobre la adaptación de la geometría al $\operatorname{lugar}^{10}$. Referían como modelo la fortificación regular, de forma que la irregular, fruto de los condicionantes geográficos y del buen hacer y experiencia del ingeniero, debía aproximarse al máximo a la primera ${ }^{11}$. En este principio se asentó la excelencia de las fortificaciones de la Monarquía española en todas sus fronteras ${ }^{12}$. Era allí donde el ingeniero debía mostrar su experiencia y maestría, y no limitarse a copiar unos modelos geométricos preconcebidos por los tratadistas ${ }^{13}$. También el modo de proyectar las plazas de costa había estado sujeto a un continuo debate. En primer lugar, se trataba de escoger unos pocos puertos, llave de cada reino, que permitieran conjugar la logística de las rutas comerciales con una buena defensa ante posibles ataques y desembarcos ${ }^{14}$. En el caso que nos ocupa, la elección había sido Cartagena, Alicante, Denia y Valencia, tratando al mismo tiempo de facilitar el comercio con los puertos de Italia. A la hora de plantear las fortificaciones, ante la continua escasez de recursos, se debatía sobre cuál era la prioridad: el aterramiento del puerto artificial, las plataformas y baterías de costa para la defensa por mar, o el cinturón abaluartado para evitar un ataque por el interior ${ }^{15}$. La intención en el caso de Alicante a partir de la segunda mitad del siglo XVII fue la de acometer todas ellas ${ }^{16}$, generando una serie de ambiciosos proyectos para la fortificación del interior, interés que se acrecentó por los hechos acaecidos en la ciudad durante la Guerra de Sucesión.

10 Para una mejor comprensión de este importante debate, Cfr. CÁMARA MUÑOZ, 2005: 149-150.

11 En muchas ocasiones las fortificaciones regulares habían tenido una mayor difusión y acogida por dos motivos fundamentales: era un modelo más fácil de exportar e internacionalizar como símbolo del poder de la Monarquía española y control del territorio, y dichos modelos provocaban menos divergencias de opinión entre los ingenieros que las irregulares. CÁMARA MUÑOZ, 2007: 52.

12 COBOS, 2005: 469-520. CÁMARA MUÑOZ, 2005.

13 No existían modelos de fortificación perfectos o ideales, a pesar de las múltiples investigaciones, debates y proyectos emprendidos. Cfr. ROSENAU, 1986: 63-73. Era el ingeniero quien debía acertar en esa adaptación al terreno, ya que era imposible dar reglas sobre el modo de realizar fortificaciones irregulares. Los ingenieros menos experimentados se limitaban simplemente a copiar modelos. CÁMARA MUÑOZ, 2005: 150.

14 COBOS, 2005: 504-509.

15 Este tipo de plazas se fortificaban únicamente por la parte de tierra. Se realizaban plataformas y baterías de artillería en la costa para repeler la acción de la flota enemiga, y se defendían de los desembarcos por la playa mediante trincheras enterradas de fajina y estacadas. CHAFRION, 1693, t. XI: 170; VAUBAN, 1689, vol. 2: 93.

16 GONZÁLEZ AVILÉS, 3532, (Madrid, 2012): 58. 


\section{EL PRIMER GRAN PROYECTO DE FORTIFICACIÓN A CARGO DEL INGENIERO AMBrosio BorÇANO}

Las tres últimas décadas del siglo se caracterizaron por los conflictos bélicos con Francia. Comienza una etapa de esfuerzos por poner las fortificaciones de la Península en condiciones de resistir asedios prolongados. Tras el comienzo de la Tercera Guerra anglo-holandesa (1672-1674), el conflicto franco-holandés (1672-1679) y la Rebelión de Mesina (1674-1678), la armada holandesa del almirante Michiel De Ruyter fue enviada en 1675 en auxilio de España. Pero tras un año de combates fracasó en Sicilia en su lucha contra la flota francesa, al no contar con efectivos suficientes. La armada francesa mostró su hegemonía en el Mediterráneo y amenazó seriamente a España ${ }^{17}$. En este preocupante escenario se redactó un proyecto general de fortificaciones para Alicante. Su autor fue Ambrosio Borçano, ingeniero militar que había intervenido en diversas plazas en Extremadura y Cataluña ${ }^{18}$. En 1677, tras ser nombrado Maestre General del Ejército de Cataluña, fue comisionado para realizar reconocimientos de todas las plazas del reino de Valencia, reconocimiento que finaliza hacia el 14 de enero de 1678. Fue entonces, con toda probabilidad, cuando elaboró el ambicioso proyecto para las fortificaciones de Alicante. Un enorme cinturón abaluartado rodearía la ciudad y sus arrabales, a la vez que un baluarte y diversas baterías de costa protegían cualquier intento de desembarco en las proximidades. La propuesta era inviable en economía y tiempo, un tanto exagerado para las posibilidades de Alicante y, tras disolverse el conflicto, se abandonó.

A pesar de que no se conserva documentación alguna sobre este proyecto, lo conocemos gracias a la información que nos transmite un plano posterior de Joseph Castellón y Pedro Joan Valero, conservado en el SGE (Fig. 1). En él se indica con trazo discontinuo la planta del proyecto de Borçano. Partiendo de un baluarte que debía ubicarse en la desembocadura del barranco de San Blas, se disponían cinco bastiones más con sus cortinas hasta alcanzar el monte Tossal. Este se rodeaba mediante murallas quebradas y baterías si-

17 La decadencia en el ámbito militar y la pérdida de la hegemonía naval durante el reinado de los Austrias menores, no implicó un decaimiento en el desarrollo científico-técnico de las fortificaciones del imperio. COBOS, 2005: 469-470.

18 Borçano inició su carrera en 1653. Tras prestar servicios en Milán y Extremadura, donde fue profesor de fortificación, es nombrado en 1669 Ingeniero Militar del Ejército de Cataluña. Más tarde asciende a Capitán e Ingeniero Mayor del Ejército de Cataluña. Tras intervenir en Gibraltar, en 1673, pasa de nuevo a Cataluña reclamado por el duque de Osuna, y es nombrado Teniente General de la Artillería del Ejército de Cataluña. En 1675 participa en el sitio de Gerona. En julio de 1681 sustituye al Ingeniero Gerónimo Rinaldi como Maestre de Campo e Ingeniero Mayor del Ejército de Cataluña. Falleció en 1698 a la edad de 66 años. IHCM, Colección Aparici, Ingenieros, t. X, p. 205. 
guiendo el relieve, y descendiendo hacia el brazo de comunicación del castillo con la ciudad, por la parte del baluarte de la Ampolla, mediante tres baluartes más. Se trataba de un buen proyecto de fortificación irregular. El proyecto incluía en el interior de la muralla los arrabales de San Francisco y San Antón, la muntanyeta de San Francisco y el monte Tossal, y suponía multiplicar por cinco la superficie envuelta por el recinto.

Resulta especialmente llamativo en el proyecto de un experto ingeniero como Borçano el hecho de que no introdujera ninguna obra exterior: revellines, contraguardias, fuertes avanzados, etc. Puede decirse que resulta contradictorio en su proyecto, ya que la enorme magnitud del recinto hacía de él un proyecto ambicioso, y las obras exteriores de fortificación se incluían siempre en este tipo de proyectos. Mayor importancia cobra si cabe la omisión de fuertes exteriores en lugares desde los cuales se retrasaran los trabajos de aproximación del enemigo.

Los anteriores inconvenientes del proyecto de Borçano, principalmente el de los costes de tan importante obra y la exigencia de una guarnición desproporcionada a las posibilidades reales de Alicante, hicieron que en proyectos posteriores se abandonara la idea de incluir el monte Tossal en el recinto. Sin embargo, el proyecto de Borçano era técnicamente un buen proyecto, y demostraba oficio y experiencia.

\section{Joseph Castellón y Pedro Joan Valero realizan un Segundo Pro- YECTO DE FORTIFICACIÓN}

Tras el ambicioso proyecto del ingeniero Borçano nos encontramos poco después con otro de menor calidad técnica. Nos referimos al que elaboraron en 1688 los ingenieros militares Joseph Castellón y Pedro Joan Valero. Nos ha quedado el plano - suficiente para comprender sus propuestas - aunque no la memoria adjunta, que no se conserva ni en el AGS ni en el AMA. La Rebelión de los barretines catalanes y el inicio de la Guerra de los Nueve Años en 1688, en que el ejército francés de Luis XIV invadió el Palatinado y Austria, obligaron a redactar proyectos de fortificación para algunas plazas estratégicas españolas.

El proyecto consistía en un recinto de forma circular compuesto de siete baluartes más un medio baluarte, y dos baterías de costa, al más puro estilo de las propuestas de la época. Comenzaba con un primer baluarte en la desembocadura del barranco de San Blas, otros que incorporaban en el interior los arrabales de San Francisco y San Antón, y la muntanyeta, y un último medio baluarte en la ladera oeste del Benacantil, próximo al brazo de conexión de la plaza con el castillo. En la parte del mar se establecía una cortina con baterías 
que finalizaba con una plataforma que cubría el baluarte redondo de San Bartolomé, de la época de Carlos V. Con este cinturón protegía a la ciudad del ataque más desfavorable posible, que era desde la playa de Babel, y del ataque naval ${ }^{19}$. No se incluían revellines delante de las cortinas, ni ninguna otra obra exterior como contraguardias o tenazas, muy frecuentes en las plazas fuertes de la época ${ }^{20}$.

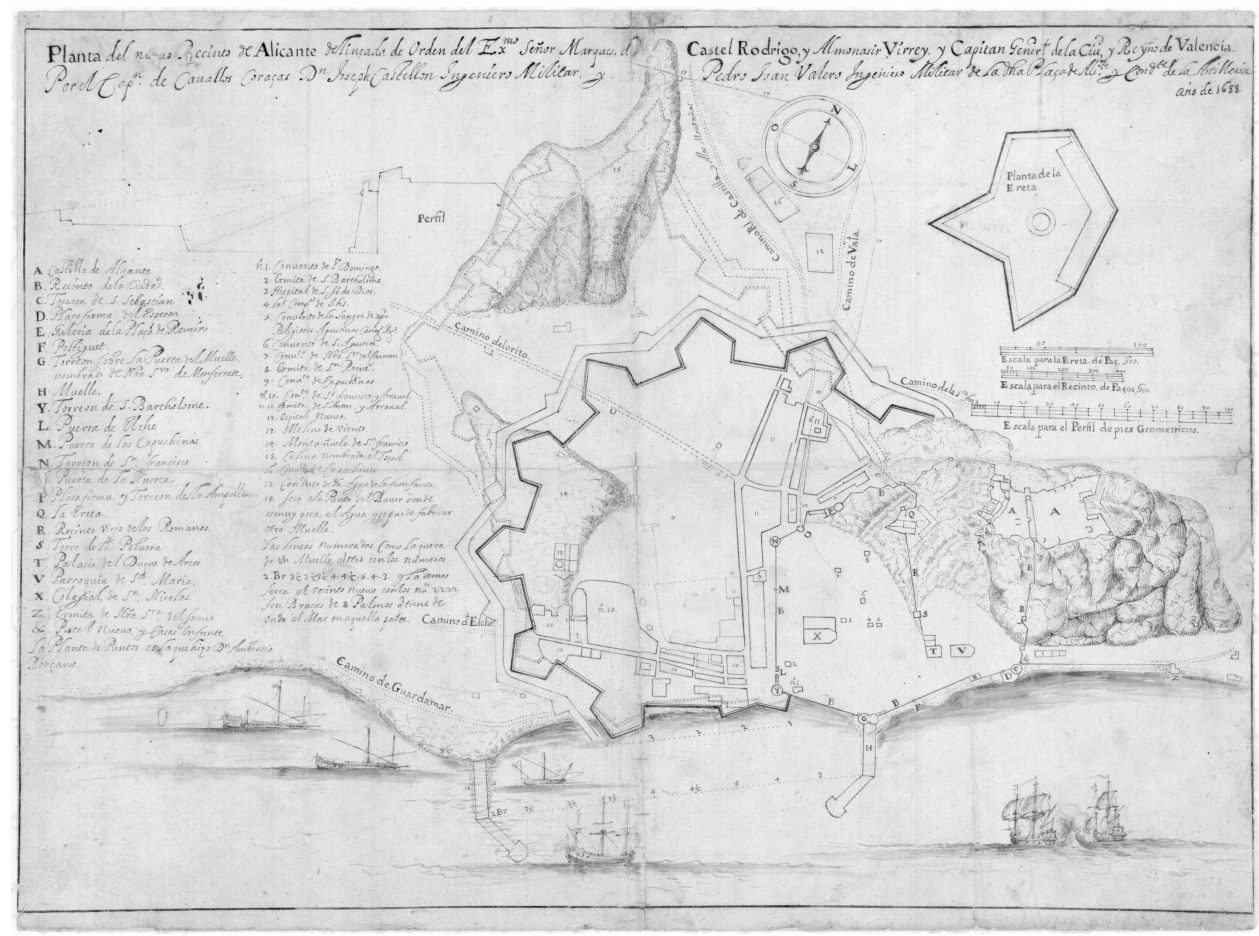

Fig. 1. «Planta Del nuevo Recinto de Alicante...». Joseph Castellón y Pedro Joan VALERO. 1688. SGE. CARTOTECA HistóRICA. AR G-T.3-C.3-287.

Sin entrar en grandes valoraciones y crítica del proyecto, diremos que, al igual que sucediera con Borçano, era un error no contar con obras exteriores de fortificación. Además el trazado del cinturón abaluartado pecaba de una

19 A. Espino hace una buena descripción del proyecto de Castellón y Valero, con la evaluación del coste previsto para las obras. ESPINO LÓPEZ, 2007: 155.

20 Para un mayor conocimiento de la labor de los ingenieros militares durante el siglo XVII, Cfr. COBOS y CASTRO FERNÁNDEZ, 2005: 71-95. GUTIÉRREZ y ESTERAS, 1991: 13. 
excesiva componente de geometría regular y adolecía de adaptación a las condiciones del relieve circundante. En el caso que nos ocupa llama poderosamente la atención que el cuarto baluarte, contando desde el mar, se implantaba en plena muntanyeta de San Francisco, es decir, a una cota superior que sus colindantes bastiones, con las dificultades de flanqueo que esta circunstancia conllevaba.

Si prestamos atención a las dimensiones propuestas por nuestros ingenieros para las caras de los baluartes y las cortinas, apreciaremos que eran similares. Los bastiones eran de mayor dimensión que los propuestos por Borçano, mientras que las cortinas eran algo menores. Tras el avance experimentado en la artillería a lo largo del siglo XVII ${ }^{21}$, ofrecer caras de bastiones demasiado amplias perjudicaba notablemente la defensa ${ }^{22}$. Además este defecto hacía que, en vez de un recinto que podría resolverse con cinco bastiones, se adoptaba uno que requería siete. Pero lo que más llama la atención es que la contraescarpa no era paralela a las caras de los baluartes, sino que el foso se estrechaba en exceso en sus puntas, tal y como lo hiciera Francesco de Marchi en algunos de sus proyectos de finales del XVI ${ }^{23}$. Los cambios sufridos en la táctica de ataque de plazas, en que el paso del foso se realizaba habitualmente por la cara de los baluartes, hacían de esta disposición un grave defecto para un proyecto de fortificación tan relevante.

\section{El baluarte de SAN CARlos}

Alicante sufrió los efectos de un terrible bombardeo por parte de la armada francesa en $1691^{24}$. A pesar de los informes y proyectos presentados por los ingenieros militares durante décadas, no se había hecho ninguna obra de forti-

21 Para una mejor comprensión de la influencia del desarrollo técnico de la artillería en la evolución de las dimensiones y proporciones del frente bastionado, Cfr. COBOS, 2005: 474480.

22 Cfr. CHAFRION, 1693, t. XI: 26. Hacer la cara del baluarte excesivamente grande motivaba que fuera más fácil abrir brecha, requería un mayor número de defensores y gran cantidad de tierra para el terraplenado. Se establecía como dimensión límite de la cara del baluarte los dos tercios y la mitad de la cortina. FERNÁDEZ DE MEDRANO, 1687: 106-107.

23 Sobre los escritos de Francesco de Marchi sobre arquitectura civil, arquitectura militar y artillería, su labor de ingeniero militar al servicio de la Monarquía española, y la influencia de sus manuscritos, Cfr. DE GROOF; BERTINI, 2000.

24 Sobre la influencia que para los proyectos de fortificación de Alicante del siglo XVIII tuvo el bombardeo de 1691, véase ESPINO LÓPEZ, 2007: 156-76. ORTS Y BOSCH, 1971: 160. Tras haber bombardeado Barcelona el 10 de julio, la flota francesa al mando del almirante D'Estrées se presentó en Alicante. Bombardeó la ciudad durante una semana, del 22 al 29 de julio, causando una decena de muertos y numerosos heridos. Fueron lanzadas 3.500 bombas que convirtieron la ciudad en un escenario desolador. 
ficación. Afortunadamente no se produjo desembarco de tropas, aunque se intentó en varias ocasiones, y todo quedó en un episodio de destrucción y terror. Las defensas apenas habían podido ofrecer resistencia, y la ciudad quedó desolada y sumida en la ruina de muchas de sus edificaciones. El bombardeo de 1691 evidenció la nula efectividad de la defensa de la plaza, y el intento de desembarco francés mostró la facilidad con que era posible tomar tierra por la playa de Babel.

Tras este terrible acontecimiento se procedió a reconstruir la ciudad. Gracias a la prosperidad que comenzó a vislumbrarse a finales de siglo, con un importante aumento de la población y una reactivación económica ${ }^{25}$, se procederá por fin a acometer algunas de las obras de fortificación de la plaza y castillo ${ }^{26}$. Ambrosio Borçano, Ingeniero Mayor de Cataluña, proyectó la construcción de un baluarte junto a la desembocadura del barranco de San Blas, cuya misión era poder batir con baterías de costa las posibles invasiones por mar, y desde tierra por la playa de Babel. Coincidía en su forma y escala con el que ya estableciera, junto al mar, en su anterior proyecto general para la plaza ${ }^{27}$.

Era un bastión bien emplazado y capaz de alojar numerosas piezas de artillería, por lo que el sistema defensivo de la ciudad inició una nueva etapa. Los trabajos adelantaron con rapidez y pronto se contó con un elemento defensivo adecuado a las necesidades de Alicante, aunque debemos mencionar que no estuvo exento de críticas por algunos expertos ingenieros. A pesar del éxito de la empresa, los trabajos de fortificación se interrumpieron, y los proyectos de dotar a Alicante de un cinturón abaluartado en todo su perímetro fueron

25 En las últimas décadas del siglo XVII el Levante español apuntó una tendencia a una recuperación demográfica y económica más temprana que el resto de la Península. La reactivación comercial se localizó sobre todo en Alicante, por su posición privilegiada de fácil acceso y salida de Castilla, en detrimento de Cartagena y Valencia. Cfr. MONTOJO, (Murcia, 2010): 47-49. El comercio de Alicante experimentó una evolución favorable al principio (1679-1689) y desfavorable durante la guerra (1689-1697), pero positiva después (16971700). Además de ser el cauce de suministros de productos manufacturados a la Corte en Madrid, funcionó también como puerto de escala para otros reinos como Inglaterra, Holanda, Flandes, Francia, Portugal, Andalucía, Mallorca, Cataluña e Italia. Cfr. MONTOJO, (Valencia, 2010-2011): 327-34.

26 Cfr. ECHARRI IRIBARREN, 16/954, (2011).

27 «He tenido aviso de Alicante como los de la Ciudad me han pedido a S.M. para que fuese alla a disponer un Baluarte que tenia trazado en la arenal y (...) pasarme a la vuelta a Alicante para unos 3 dias a disponerle aquel travajo supuesto que es mi traza, que desto lo dejare a la disposicion de V.S...».Carta del Ingeniero Mayor Ambrosio Borçano al Capitán General marqués de Villanueva. 21 de noviembre de 1691. IHCM, Colección Aparici, Ingenieros, t. X, p. 205. Queda manifiesta por tanto su autoría, y no debe atribuirse a los ingenieros Castellón y Valero. 
desestimados ${ }^{28}$. El baluarte de San Carlos pasó a ser el único elemento defensivo moderno de la ciudad.

\section{Las fortificaciones de Alicante durante la Guerra de Sucesión. EL TRINCHERÓN DE LOS INGLESES}

Pocos años después, durante la Guerra de Sucesión, la ciudad fue puesta a prueba mediante un sitio regular con tropas de infantería por el interior y una poderosa flota desde el mar $^{29}$. El baluarte de San Carlos apenas pudo ofrecer resistencia. El 4 de septiembre de 1706 las tropas aliadas, bajo el mando del General Leake y el Major-General Richard Gorges, tomaron Alicante y su castillo en pocos días, tras abrir dos brechas en las obsoletas murallas de Carlos V.

Conocemos por documentos posteriores que el nuevo gobernador Gorges acometió obras de fortificación importantes en la ciudad y el castillo, que se encargó de finalizar su sucesor, el General John Richards, a partir de marzo de 1707. Encargó al ingeniero Pierre de Pagez que redactara un proyecto, mucho más modesto que los anteriores, con el que resolver las deficiencias que mostraba la plaza,. Se construyó un trincherón que, partiendo desde el baluarte de San Carlos, y dejando fuera el convento de los Capuchinos, envolvía el arrabal de San Francisco; y un baluarte bajo y falsa braga en la parte norte del castillo, delante del frente que construyera el Fratín. La fisonomía de las fortificaciones de Alicante se vio totalmente modificada, aunque el trincherón no pasó de ser un maquillaje de defensa, tal y como opinaba Richards ${ }^{30}$; construcción a base de mampuesto, sin foso, contraescarpa, camino cubierto ni terraplenes de tierra hacia el interior.

Con facilidad, y en apenas dos días de sitio, el General D'Asfeld, al mando de las tropas filipistas, entraba victorioso en la ciudad por el arrabal de San Antón el 3 de diciembre de 1708. La toma del castillo fue sin embargo mucho más compleja. La estrategia de D’Asfeld consistió en iniciar los trabajos de una mina, tarea francamente arriesgada. Algunos pensaban que no era posible

28 Como describe A. Espino, el coste de las obras del baluarte fue de 230.000 reales de plata, cantidad importante si tenemos en cuenta los escasos recursos de la ciudad y la Real Hacienda. Si lo comparamos con la estimación que hace Valero del coste de las obras de su proyecto - alrededor de 1.000.000 de reales - parece indicar que éste se quedó muy corto en dicha valoración. Cfr. ESPINO LÓPEZ, 2007: 175.

29 Según López y Maltés se «dispararon 135 balas, y quatro mil bombas y granadas» durante seis días. MALTÉS; LÓPEZ, 1907: 406.

30 En cuanto a continuar con el trincherón, la decisión no fue fácil. Juzgaba el gobernador más efectivo defender el castillo, que consideraba inexpugnable. Carta de Richards a Alvaro Cienfuegos. 21 de mayo de 1707. BL, Manuscripts, Stowe 474, Richards Collections, Vol. XXVIII, p. 52 v. 
minarlo por la aparente fortaleza de la roca en que se asentaba ${ }^{31}$. Los trabajos ordenados por el general francés dieron sus frutos el 3 de marzo de 1709, cuando 52,5 toneladas de pólvora hicieron saltar por los aires algunas partes del castillo y gran parte de la montaña de roca en que se asentaba, muriendo el general John Richards y algunos de los oficiales británicos. Los aliados abandonaron la fortaleza el 19 de abril.

Tras la toma del castillo, los franceses realizaron un plano del estado de la ciudad y sus arrabales en 1709. La finalidad no era otra que ser la base de elaboración de un nuevo proyecto de fortificación ${ }^{32}$. Se introducían dos nuevos baluartes sobre el arrabal, que se podría defender mejor. El proyecto de los franceses corregía sin duda algunos errores del trincherón de los ingleses. Como venía ocurriendo con todos los proyectos elaborados en el siglo XVII por orden real, no se ejecutó obra alguna. Hubo que esperar a que finalizara la Guerra de Sucesión para acometer el tan ansiado proyecto de fortificación abaluartada que pusiera Alicante en verdadero estado de defensa.

\section{JORGE PRÓSPERO de VERBoOM ES NOMBRAdo INGENIERo GENERAL}

Apenas nueve meses después de la toma de Alicante por las tropas filipistas, el 10 de enero de 1710, Jorge Próspero de Verboom fue nombrado Ingeniero General y Cuartel Maestre General de todos los ejércitos españoles ${ }^{33}$. Felipe $\mathrm{V}$ quiso establecer un sistema organizativo basado en el modelo francés de Luis XIV, quien había otorgado toda responsabilidad de las fortificaciones francesas a Sébastien le Prestre de Vauban ${ }^{34}$, verdadero genio que sistematizó la guerra de sitios y estableció sistemas defensivos admirados en toda Europa. El sistema centralizado francés se adoptó también en la formación de los ingenieros militares, quienes al intervenir en conflictos bélicos, aplicaron las máximas de Vauban en numerosas plazas europeas.

Verboom había disfrutado de una formación y experiencia de la guerra exquisita $^{35}$. Se había formado en la Academia Real y Militar del Ejército de los

31 BENDICHO, Parte Primera, Lib. 1, Cap. XIII.

32 Cfr. GONZÁLEZ AVILÉS, 7/25, (Madrid, 2012).

33 CAPEL, SANCHEZ y MONCADA, 1988: 22-25.

34 Sobre lo que supuso Vauban y la influencia en la fortificación de finales del XVII y el XVIII, véase WARMOES, 2007: 190-197, y todo el catálogo de la exposición.

35 Jorge Próspero de Verboom nació en Amberes en 1665. Estudió en la Real Academia Militar del Ejército de los Países Bajos en Bruselas, donde fue discípulo de Sebastián Fernández de Medrano. El 8 de octubre de 1692 fue nombrado Capitán de Infantería. Posteriormente Cuartel Maestre General e Ingeniero Mayor de los Ejércitos Españoles en los Países Bajos, sucediendo en el cargo a su padre Cornelio de Verboom. Participó activamente en la Guerra de Sucesión, encargándose de la defensa de Amberes y otras plazas de los Países Bajos. 
Países Bajos, dirigida por Sebastián Fernández de Medrano ${ }^{36}$. Su carrera fue meteórica, y con apenas 27 años fue nombrado Cuartel Maestre e Ingeniero Mayor. Participó en campañas junto a Van Coehoorn, como en Namur en 1695, y posteriormente con Vauban en el sitio de Hulst y otros trabajos en Amberes y Namur en $1702^{37}$, una vez que fuera nombrado Ingeniero General del Ejército de los Países Bajos, con tan solo 37 años de edad.

El papel de Verboom fue decisivo para acometer una reforma imprescindible en el modo de organizar el cuerpo de ingenieros militares ${ }^{38}$ y la práctica de una profesión que debía servir de enlace entre la provincia y el poder central, algo que en Francia se había entendido medio siglo antes. Verboom abogaba por suprimir la antigüedad y las relaciones dentro del cuerpo como criterios de ascenso, y proponía el mérito y la capacidad, unidas a un notable esfuerzo por la formación científica, como herramientas para garantizar la competencia técnica de los ingenieros militares ${ }^{39}$. Se habían cometido numerosos errores en el diseño y construcción de las fortificaciones en España, como los fracasos de Fraga y Lérida durante la Guerra de Sucesión ${ }^{40}$. El rey

(BRAGARD, 2011: 215-217). En 1709 llega a Madrid y es nombrado Teniente General e Ingeniero General de los Reales Ejércitos. Se le encargó por entonces la organización del Cuerpo de Ingenieros.

En 1713-14 participó con Berwick en el sitio de Barcelona. Al año siguiente elaboró el proyecto de la ciudadela de Barcelona. En 1716 es nombrado Teniente General de los Ejércitos, y en 1718 gobernador y castellano de la ciudadela de Barcelona. Participó en la expedición española a Cerdeña y Sicilia (1717-1718), donde dirigió con éxito el sitio de Mesina, aumentando todavía más su prestigio.

Entre 1720 y 1724 reside entre Alicante, Cartagena, Málaga, Ceuta y Cádiz redactando diversos proyectos de fortificación. En 1725 se encuentra en Pamplona donde, al año siguiente, redactó el proyecto general de sus fortificaciones (Cfr. ECHARRI IRIBARREN, 2000: 418-431). En 1727 participó en el sitio de Gibraltar. En los años siguientes trabaja en Denia, Gibraltar, Barcelona y Cádiz. En 1737 ascendió a Capitán General. Posteriormente, en 1742, realizó un proyecto de la prolongación del muelle del puerto de Barcelona. Falleció en dicha ciudad el 19 de enero de 1744. WAWERMANS, 1894. Hoja de servicios de Verboom, en SHM, Colección Aparici, t. LIV, 6050. CAPEL, SANCHEZ y MONCADA, 1988: 14-56.

36 Verboom colaboró en la delineación de algunas láminas de su mejor tratado. Cfr. FERNÁNDEZ DE MEDRANO, 1700.

37 Cabe destacar la misión de espionaje al fuerte de Liekfenshoek, próximo a Amberes, y la memoria de reparaciones que se requerían para Namur, que Vauban prefirió a la que él mismo había elaborado, muestra de la alta competencia de nuestro ingeniero. BRAGARD, 2011: 216.

38 Algunos de los ingenieros con los que contó Verboom en su ingente tarea de modernizar las fortificaciones españolas provenían de Flandes, y habían colaborado con él en algunas campañas bélicas. Cfr. MUÑOZ CORBALÁN, 1993.

39 Para mayor conocimiento de esta importante transformación véase el Plan General de los Ingenieros de los Ejércitos y Plazas de 17 de abril de 1711, que elaboró Verboom. CAPEL, SANCHEZ y MONCADA, 1988: 25-32.

40 GALLAND, 2008: 35. 
así lo manifestaba en el preámbulo de la Real Ordenanza e instrucción para ingenieros que elaboró Verboom y que promulgó el 4 de julio de $1718^{41}$. El propio Ingeniero General iba a servir de modelo por su amplia formación científica, abundante redacción de proyectos y experiencia en la guerra de sitios, aunando en su persona el «ingeniero de plaza» y el «ingeniero de guerra ${ }^{42}$. De la experiencia y buen hacer de Verboom en la Península nos han quedado algunos proyectos de fortificación de gran calidad técnica ${ }^{43}$.

\section{El Proyecto General de Jorge Próspero de Verboom en 1721}

La documentación conservada en el AMA muestra algunas noticias relacionadas con la construcción del baluarte de San Carlos, pero prácticamente ninguna sobre los proyectos elaborados por ingenieros militares para las fortificaciones de la ciudad. Durante el siglo XVII no hubo apenas intervenciones ni proyectos que resaltar, salvo el mencionado de Castellón y Valero. Algo similar sucede por lo que respecta al AGS. No hay constancia del proyecto de dichos ingenieros, ni tampoco del que elaboró Ambrosio Borçano pocos años antes de 1688. Lo mismo sucede desde 1692, así como de lo referente a los años de la Guerra de Sucesión, hasta el año 1716.

Esta carencia de documentos se ve recompensada por la abundancia de planos y documentos conservados en el AGS y otros archivos militares como el del IHCM, y el SGE, a partir de 1716. El primer plano posterior a la Guerra de Sucesión refleja un proyecto general para las fortificaciones de Alicante (Fig. 2). Se conserva en el SGE. Es de un enorme valor por la calidad de sus propuestas y la precisión gráfica con que está trazado. Conociendo otros proyectos similares del Ingeniero General Jorge Próspero de Verboom para algunas plazas españolas tras finalizar la Guerra de Sucesión, como los de Cartagena, Pamplona, Fuenterrabía o San Sebastián, podemos deducir que fue sin duda su autor. De entre la abundante cartografía que se elaboró tras la Guerra de Sucesión en España, solamente esta serie de planos, elaborados entre 1721

41 CAPEL, 2005: 246-247.

42 Simon Poulet de Monfoison, en sus «Réflexions sur ce qui paroist le plus convenir au service de S.M. sur les ordonnances du Corps des Ingénieurs» manifestaba la importancia de la superioridad del ingeniero de guerra sobre el de plaza, un defecto patente en el sistema español, y que urgía reformar. Cfr. GALLAND, 2008: 48-51.

43 Cabría destacar entre estos proyectos el de la ciudadela pentagonal de Barcelona de 1715, en que seguía el modelo establecido por Vauban, aunque no introducía tenazas delante de las cortinas (VAUBAN, 1737: 106-108; 1689, vol. 2: 113-114); el proyecto general para Alicante de 1721, que el autor atribuye a Verboom; el que elaboró para Ceuta en 1722-1723; y el proyecto general para las fortificaciones de Pamplona de 1726. Cfr. ECHARRI IRIBARREN, 2000: 418-431. 
y 1726, presentan una precisión geográfica exquisita -inexistente en la cartografía española anterior - en la descripción de la plaza, sus fortificaciones, y una extensión de terreno de alrededor de media legua, distancia a la que se entendía que se establecería el enemigo en caso de sitio ${ }^{44}$. Además sólo Verboom firmaba en la leyenda de sus planos «Proyecto General». Sabemos por su biografía que, tras regresar a Barcelona en 1719 tras las campañas de Cerdeña y Sicilia ${ }^{45}$, residió entre Alicante, Cartagena y Málaga en 1720-1722, realizando algunos proyectos de fortificación ${ }^{46}$. En 1721 visitó el pantano de Tibi, construido por mandato de Felipe II, y que precisaba obras de reparación y solidificación de su presa, elaborando una serie de planos y memorias que se han conservado en el AGS ${ }^{47}$. Además la Real Ordenanza del Cuerpo de Ingenieros de 4 de julio de 1718 disponía que el Ingeniero General realizara un reconocimiento de todas las plazas y puertos de mar, formando planos y memorias de ellas; y que cuando él se encontrara en alguna plaza, no se hiciera ninguna propuesta de fortificación sin su proyecto personal y supervisión ${ }^{48}$.

A pesar de no contar con ningún documento que avale su estancia en Alicante, ni sus trabajos de inspección de la plaza y castillo, conocemos que tenía mandato real de pasar por la ciudad. Alicante, bombardeada brutalmente treinta años antes, había sido una de las plazas más importantes desde el punto de vista táctico de la Guerra de Sucesión y requería, al igual que las plazas más importantes de la Corona, un moderno proyecto general de fortificación. Verboom priorizó Alicante frente a otras plazas del Mediterráneo a la hora de planificar la defensa territorial. A su paso por Cartagena, el mismo año 1721, que había sido igualmente sitiada y tomada por tierra por las tropas aliadas durante la Guerra de Sucesión, dejó un proyecto de amejoramiento del puerto, pero decidió no proponer un nuevo cinturón abaluartado por el interior ${ }^{49}$. La

44 GALLAND, 2008: 40.

45 Guerra de Cerdeña y Sicilia en los años 1717-1720, Primera Parte, Manuscrito, BNE, MSS/6310.

46 WAWERMANS, 1894: 105-110.

47 Cfr. ALBEROLA, 1979: 65-91. CAMARERO CASAS y BEVIA GARCÍA, 1989.

48 Se establecía en la disposición $n^{\circ} 46$ que «...en cualquiera Provincia donde se hallare el Ingeniero General de mis Exércitos, Plazas y Fronteras, no se proponga, ni se haga obra nueva, ni reparos, sin que preceda su examen, y parecer, como también la instrucción de la forma en que se hubiere de executar,...», y más adelante, en la $n^{\circ} 47$, «Quiero también que el referido Ingeniero General se dedique a reconocer por sí mismo todas las Plazas, Fronteras, Puertos de Mar, y Costas, y que asistido de los Ingenieros Subalternos que le siguieren, forme los Planos, Relaciones, y demás observaciones, y diligencias que se encargan a los Ingenieros Directores de cada Provincia a fin de que pueda informarme de todo...». AGS, Guerra y Marina, legajo 2991.

49 SGE, Cartoteca Histórica, Ar G-T.4-C.1-43. Este plano puede atribuirse a Jorge Próspero de Verboom, quien en compañía de su hijo Isidro y otros ingenieros se encontraban en Cartagena en agosto de 1721. Carta del ministro José Grimaldo a Verboom de agosto de 1721. AGS. Guerra y Marina, legajo 3610. 
escasez de medios obligaba a una austera política general de fortificación. Por lo que respecta a Alicante, además de la importancia estratégica para la defensa, su puerto estaba llamado a experimentar un gran crecimiento en sus operaciones de comercio por su excelente comunicación con el interior de la Península ${ }^{50}$, y necesitaba de una adecuada plaza fortificada. Así lo entendían en la Corte, y por eso esperaba Felipe $\mathrm{V}$ un gran proyecto de su mejor ingeniero. Nadie más indicado que Verboom para acometer esa tarea.

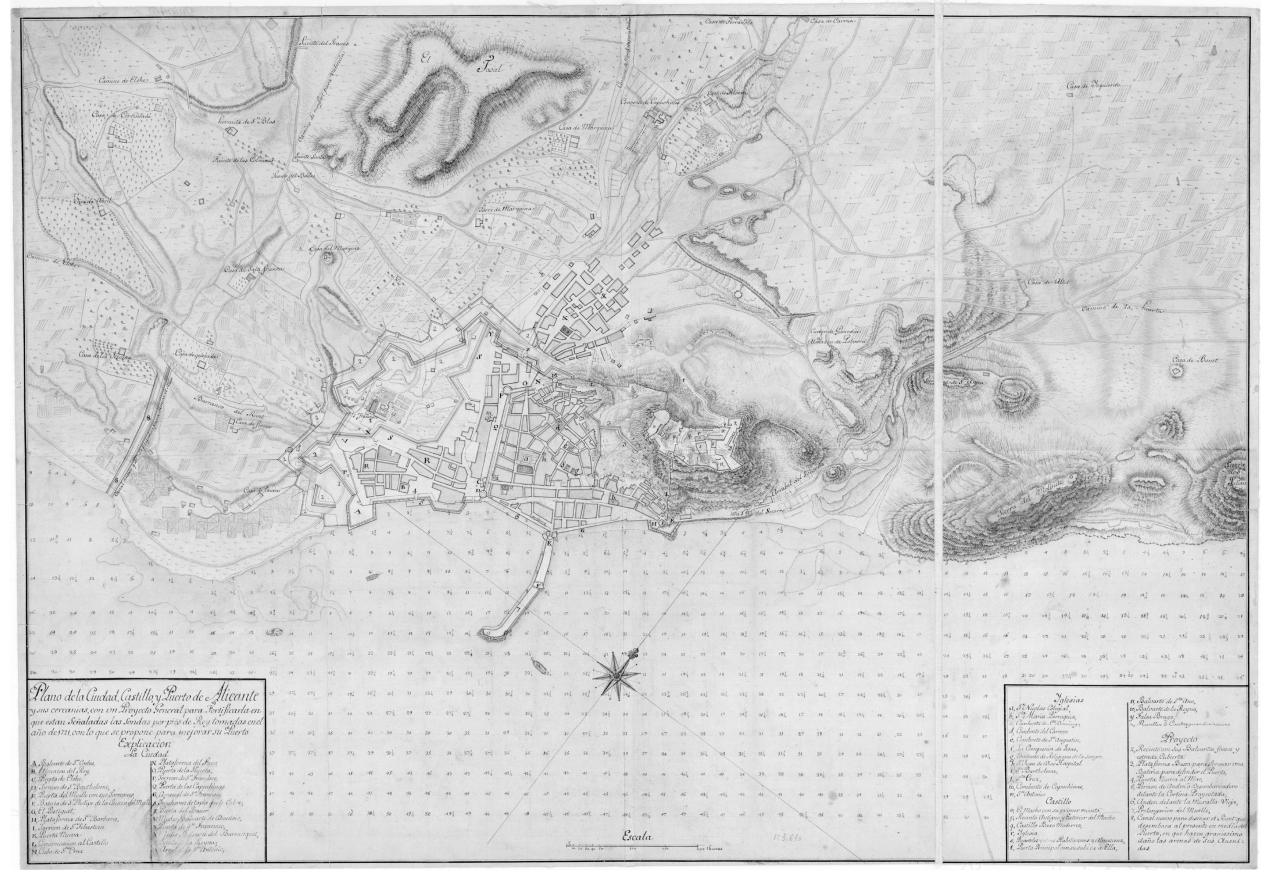

Fig. 2. «Plano de la Ciudad, CAStillo y Puerto de AlicANTe y Sus Cercanías, CON Un ProYECTO GENERAL PARA FORTIFICARLA EN QUE ESTÁN SEÑALADAS LAS SENDAS POR PIES DE REY TOMADAS EN EL AÑO DE 1721, CON LO QUE SE PROPONE PARA MEJORAR SU PUERTO ». ATRIBUIDO POR EL AUTOR A JoRge PróSPERO DE VERBOOM. SGE. CARTOTECA HistÓRICA. AR G-T.3-C.3-297.

50 Tras la Guerra de Sucesión, el puerto de Alicante fue el elemento dinamizador de la economía y las transformaciones de la ciudad. (Cfr. GIMÉNEZ LÓPEZ, 1981: 401-405). Por eso era de vital importancia evitar los sedimentos que el barranco de San Blas depositaba en el puerto, así como los efectos nocivos del barranco del Canicia en los almacenes del comercio. Las reparaciones efectuadas en el pantano de Tibi en 1737, que había sufrido importantes rupturas en 1697, supusieron un nuevo florecimiento de la producción agraria. La pugna por la supremacía sobre el puerto de Valencia fue una constante a lo largo del siglo XVIII, hasta que en 1785 el puerto de Alicante fue designado sede del alicantino Consulado de Comercio tras un intenso proceso de lucha de intereses. Cfr. GIMÉNEZ LÓPEZ, 1981: 237-248. 
El proyecto general de Verboom es un proyecto de corte personal, que parte de la base de los proyectos antes comentados, y que se denota sin duda influenciado por algunas de las máximas de Vauban ${ }^{51}$. A pesar de haber estudiado los proyectos de Borçano y Castellón y Valero, como era preceptivo, y muy probablemente los de otros ingenieros como expondremos posteriormente, Verboom realizó un proyecto de gran calidad técnica, cuajado de propuestas personales, que distaba mucho de las ideas de sus predecesores. En primer lugar proyectaba un cinturón abaluartado, que incluía el baluarte de San Carlos como única pieza bien proporcionada y dotada de troneras de costa, con el que cerraba la ciudad por el suroeste. Establecía, si añadimos el bastión inmerso en el mar delante de la torre de San Bartolomé, seis baluartes y medio en el nuevo recinto, en vez de los ocho y medio de los anteriores ingenieros. El diseño de los frentes de Verboom era bien distinto: los baluartes eran más pequeños, principalmente sus caras, y las cortinas de mayor longitud. Tendía por tanto a economizar la construcción - grave defecto del proyecto de Borçano-, bien avalada además por las máximas de Vauban y Fernández de Medrano, que establecían una distancia de flanqueo en función del tiro eficaz del mosquete ${ }^{52}$ - unos $240 \mathrm{~m}$. - y una proporción entre la cortina y la cara o frente del bastión de dos a uno y medio ${ }^{53}$. Esta menor dimensión de las caras de los baluartes era más satisfactoria que la proyectada por Castellón y Valero, como ya se indicó al hablar de su proyecto.

El trazado del cinturón abaluartado variaba ligeramente. No se extendía tan al norte como el de Castellón y Valero, y abarcaba también menos superficie en el interior para posible expansión de la edificación de la ciudad. Mientras que Castellón y Valero establecían sobre plano una geometría totalmente regular, Verboom se adaptaba sin embargo a las condiciones de la topografía para ubicar con precisión sus baluartes. Se destaca esta característica principalmente en el baluarte situado delante del convento de San Fran-

51 CARRILLO DE ALBORNOZ Y GALBEÑO, 2003: 316.

52 WARMOES, 2007: 195. La mayoría de autores así lo entendía. (Cfr. VAUBAN, 1689, vol. 2: 90. FERNÁNDEZ DE MEDRANO, 1700: 106-107). Algunos matizaban que era preferible diseñar elementos desde los que se pudiera emplear tanto el mosquete como la artillería. (CHAFRION, 1693, t. XI: 8). Según Chafrion, Vauban no había aportado nada nuevo en este terreno, sino que seguía lo establecido por Marchi y Bonaiuto Lorini. El primero establecía una línea de defensa de 826 pies de París —unos 240 metros-, por 816 del segundo y 875 del tercero. (CHAFRION, 1693, t. XI: 26). Las fortificaciones emprendidas por la Monarquía española en el siglo XVI tuvieron la virtud de haber establecido el alcance del tiro de arcabuz como distancia de flanqueo. CÁMARA MUÑOZ, 2005: 146-147.

53 A finales del siglo XVI Marchi había establecido como arco de proporción ideal del frente de fortificación regular entre cortina y frente de bastión de 2 a 1,3 y 2 a 1,5. Fernández de Medrano y Vauban seguían el mismo parecer. (CHAFRION, 1693, t. XI: 18). La cara del bastión no debía nunca ser menor de la mitad de la cortina. VAUBAN, 1689, vol. 2: 90. 
cisco, en que su cara izquierda se ajusta al relieve del terreno; en el baluarte contiguo, que tiene sus caras desiguales también por la orografía del terreno exterior; y en el frente próximo al barrio de San Antón, en que la cortina es de mayores dimensiones. Podemos concluir que el proyecto de Verboom era más próximo al de Borçano en este sentido de adaptación al terreno ${ }^{54}$, y era fruto de su dilatada experiencia en la guerra de sitios $^{55}$. Se adecuaba mejor a los avances en materia de artillería y fortificación, mientras que el de Castellón y Valero se guiaba más por presupuestos de buscar la perfección de la defensa en la geometría regular ${ }^{56}$.

Pero lo más destacable se centra en la disposición del foso y el camino cubierto. A diferencia de Castellón y Valero, fiel a las enseñanzas de Fernández de Medrano y de Vauban, hacía la contraescarpa paralela a las caras de los bastiones, a una separación adecuada para batir eficazmente al enemigo desde las casamatas en el momento de cruzar el foso ${ }^{57}$. Y es muy significativo que Verboom, en el encuentro de las plazas de armas con el camino cubierto, dispone de traversas para evitar el efecto del tiro de rebote, que el propio Vauban inventara a finales del siglo XVII ${ }^{58}$. Esta aportación denota la modernidad y precisión de su proyecto.

Otra diferencia que debe destacarse es que delante de la cortina entre el baluarte de San Carlos y el contiguo hacia el interior disponía un revellín. Se

54 CÁMARA MUÑOZ, 1993: 149-174.

55 La formación de los ingenieros militares en la segunda mitad del siglo XVII era en general deficiente, tanto en cuestiones técnicas como en la representación o dibujo de los proyectos de fortificación. Experiencia y ciencia eran fundamentales para su formación, y Verboom contaba con un importante bagaje frente a ingenieros como Castellón y Valero. CÁMARA MUÑOZ, 2003: 137-138.

56 I. Warmoes expone con su amplia experiencia la evolución de la obra de Vauban en esta continua adaptación de la geometría al lugar, en la que ya no se imponían reglas ni sistemas, sino el buen hacer y la experiencia del ingeniero: "Cést ici l'écueil des ingénieurs et où toute leur science est à bout», témoignant combien la gestion de ces reliefs lui semblait difficile. Plus tard encore, en 1700, alors qu'il est dans les Alpes, il exprimera de nouveau son désarroi depuis Seyne: «Toutes les Maximes de la fortification sont à bout, si bien que si on veut tirer parti, il faut en arracher les moyens de sa tête comme on peut». WARMOES, 2007: 196.

57 Chafrion, en su análisis de las máximas de fortificación que habían establecido los ingenieros más prestigiosos, señalaba como característico este paralelismo contraescarpa-frente del bastión. (CHAFRION, 1693, t. XI: 136). El prestigioso ingeniero de Felipe II, Fratín, disponía los fosos en ángulo divergente hacia el vértice del bastión. Era una disposición enteramente insólita. Francesco de Marchi, había diseñado, a mediados del siglo, fortificaciones donde los fosos se estrechan hacia los vértices de los baluartes, justamente al contrario que Fratín. Cfr. ECHARRI IRIBARREN, 2000: 146-147.

${ }^{58}$ Una gran aportación del propio Sebastián Le Prestre Vauban fue la invención del «tir à ricochet», tiro de rebote. Éste consistía en reducir la carga de pólvora, de modo que la bala iba rebotando a lo largo del camino cubierto, destruyendo imprevistamente cuanto encontraba a su paso. Fue el propio Vauban quien diseñó traveses o traversas para evitar los efectos de esta técnica. Cfr. VAUBAN, 1689: vol. 2, 73-75. 
refería ya en la leyenda al baluarte de San Carlos con su nombre y forma definitiva, y por tanto debemos entender que debía de estar ya construido, aunque no sepamos con precisión si estaban totalmente finalizados los encamisamientos, banquetas, etc. Entendía Verboom que era un frente más desfavorable para la defensa, y que por tanto debía reforzarse con este elemento, de forma que el enemigo hubiera de emplear mayor tiempo en poder abrir brecha en los bastiones por esta parte, ya que el debería en primer lugar desalojar de allí a los defensores.

El cinturón abaluartado proyectado por Verboom desestimaba por tanto el trincherón construido por los ingleses durante los dos años de ocupación -17061708 - por ser una obra absolutamente ineficaz, carente de flanqueo, de foso y camino cubierto protegido del tiro de rebote; hacía otro tanto con el proyecto del ingeniero Ambrosio Borçano, por estimarlo excesivamente ambicioso en su trazado, ya que planteaba un recorrido longitudinal tres veces superior al incorporar el monte Tossal; y difería en el diseño y trazado del proyecto de Castellón y Valero, carente además de una buena disposición de fosos y de protección contra el tiro de rebote.

Por lo que respecta al frente marítimo y puerto proyectaba, a continuación del baluarte de San Carlos, una cortina y un medio baluarte que enlazaba con la existente muralla de Carlos V. Añadía un embarcadero delante y una nueva puerta hacia el mar. Mantenía un medio baluarte con otras baterías de costa delante de la torre de San Sebastián, enlazando por la otra parte con la muralla del siglo XVI. Tal y como se hiciera en repetidas ocasiones, proyectaba prolongar el muelle del puerto, por ser insuficiente para el atraque de barcos, disponiendo en su extremo una importante batería defensiva.

Desde que se estableciera el puerto comercial en Alicante, las avenidas del barranco del Rivet, más tarde denominado de San Blas, las arenas y detritos que arrastraba en épocas de fuertes lluvias del otoño, causaban daños en el puerto, disminuyendo su capacidad de fondeo, y poniendo en peligro su viabilidad en el futuro. Algo similar sucedía con el barranco de Canicia, proveniente del arrabal de San Antón por el norte. Además, desde que se construyera el baluarte de San Carlos, estas aguas producían daños en sus sólidos muros y cimientos. En su afán de batir eficazmente la aproximación del enemigo desde el mar, la cara derecha del baluarte quedaba pegada a la orilla de la desembocadura del barranco. Un defecto a priori insalvable. Verboom proponía solucionar el problema con el cierre del cauce natural mediante un paredón reforzado, y la formación de un canal que desviara el cauce del barranco y lo enviara hacia el mar por la parte de Babel, unos 500 metros antes de la desembocadu$\mathrm{ra}^{59}$. Su experiencia en los trabajos desarrollados en los Países Bajos, donde

\footnotetext{
59 ECHARRI IRIBARREN, 16/ 954, (2011).
} 
este tipo de obras eran de común administración, le valió para plantear esta audaz iniciativa $^{60}$. Por primera vez en la historia de las fortificaciones de Alicante, según se desprende de la documentación conservada en los archivos militares de Madrid, el AGS y el AMA, se hacía referencia de los perjuicios que causaba el barranco de San Blas y de la necesidad de desviar su cauce:

«8. Canal nuevo para desviar el Rivet que desemboca al presente en medio del Puerto, en que hazen gravissimo daño las arenas de sus Avenidas» ${ }^{61}$.

Podemos adelantar que medio siglo después, en 1772, ya fallecido Verboom, se construyó dicho canal, pero no exactamente según su trazado. Unas fuertes avenidas se llevaron por delante el paredón que cerraba el paso al antiguo cauce, motivado por los remolinos ocasionados en la curva que hacía el barranco ${ }^{62}$. Proyectos posteriores como los de los ingenieros Antonio Exarch o Pedro Antonio de Molina trataron de solucionar este problema ${ }^{63}$. A pesar de los defectos señalados, Verboom acertó de pleno con su idea de desviar el cauce del barranco de San Blas, y supuso una garantía para la viabilidad del puerto de Alicante en el transcurrir del tiempo.

Siguiendo con otras aportaciones, Verboom proyectaba una plataforma con baterías en la parte de la Ereta, a media ladera del Benacantil, entre la ciudad y el castillo. Este punto era vital, y fue tratado por todos los ingenieros de los que nos han quedado información de sus proyectos, empezando por Ambrosio Borçano. La razón principal era que desde el castillo, debido a la vertiginosa pendiente que descubría sobre el mar, no era posible batir bien el puerto. La Ereta era un lugar idóneo para esta misión, incluso para poner en apuros al enemigo en su aproximación desde la parte de la puerta de la Huerta.

La última de las obras proyectadas por Verboom es una plataforma a modo de medio bastión delante del torreón de San Sebastián, próxima al mar, rehaciendo y mejorando la existente «plataforma del Esperón». La denominaba «Plataforma de Santa Bárbara». Era una pieza importante para poder batir

60 LLAVE y GARCÍA, 28 (Madrid, 1911): 109-115.

61 SGE, Cartoteca Histórica, Ar G-T.3-C.3-297.

62 Fueron frecuentes los episodios en que las crecidas de los barrancos de San Blas y Canicia causaron estragos en las fortificaciones, principalmente en el baluarte de San Carlos y en el frente de Bavel. En 1552, 1772, 1783, 1793 y 1797 las aguas descarnaron los cimientos de la espalda de la cara derecha del baluarte de San Carlos y su cortina adyacente, cuarteándola y ocasionando numerosos desprendimientos de la mampostería y sillería. El malecón que cerraba el paso de las aguas al antiguo canal no fue capaz de resistir las embestidas. Cfr. ECHARRI IRIBARREN, 16/954, (2011).

${ }^{63}$ Plano que comprende el curso natural del barranco de San Blas... Antonio Exarch, 20 de marzo de 1783, AGS, M, P y D. IV-166, Guerra y Marina, legajo 3488. Plano del cause de San Blas y terreno ynmediato... Pedro Antonio de Molina. 16 de octubre 1783. IHCM, Cartoteca, A-01-20b 013126. 
cruzadamente la zona del puerto, además de las posibles aproximaciones de una armada desde la costa por el nordeste.

El proyecto de Jorge Próspero de Verboom es probablemente el mejor proyecto que llegó a proponerse para las fortificaciones de Alicante a lo largo de toda su historia. Tenía grandes virtudes, entre ellas la proporción entre el coste de las obras - más bajo que el planteado por otros ingenieros - y la calidad defensiva que proporcionaba. Fue uno de sus primeros proyectos generales, desarrollado en el tiempo entre dos de sus obras maestras, la ciudadela de Barcelona y el proyecto de fuertes exteriores de Pamplona, y muestra su excepcional calidad como ingeniero proyectista. Sin embargo, este proyecto general no llegó a realizarse en la mayor parte de sus propuestas. Se mantuvo durante todo el sigo XVIII el trincherón de los ingleses, débil e incapaz de resistir apenas unos días de asedio. Sin embargo, el desvío del cauce del barranco de San Blas por él proyectado se llevó a la práctica varias décadas después, por ser absolutamente necesario.

\section{Otros PROYECTOS DE INGENIEROS DESARROLlados EN 1721: Diego FA- BRÉ Y JUAN BALLESTER Y ZAFRA}

Se conservan el SGE algunos planos de 1721 elaborados por ingenieros militares, en los que se lanzan propuestas de fortificación de la ciudad por la parte de San Francisco. Desgraciadamente no se han encontrado memorias adjuntas de ninguno de los proyectos en el SGE, el AGS y el AHN. Al no tener referencias sobre el mes en que se delinearon dichos planos, no podemos saber si fueron previos al proyecto general de Jorge Próspero de Verboom, o por el contrario fueron posteriores. Tal y como estaba reglamentado y establecido administrativamente, éstos se llevaron a cabo por indicación expresa de Verboom $^{64}$. La primera de las hipótesis es que, al igual que sucediera en otras ocasiones, Verboom hubiera ordenado a algunos ingenieros de la plaza de Alicante y otros de la demarcación, que hicieran proyectos de fortificación para la plaza de Alicante ${ }^{65}$. Y una vez estudiados, haciendo un re-

${ }^{64}$ En la Real Ordenanza e Instrucción de 4 de julio de 1718 se establecía que los ingenieros residentes en las plazas debían hacer con frecuencia relaciones de reparos, y en el $n^{\circ} 44$ «...que el Ingeniero Director de cada Provincia visite de quando en quando las Plazas de su distrito, para reconocer, y formar Relaciones, y Proyectos de los reparos, obras y demás providencias...». AGS, Guerra y Marina, legajo 2991.

65 Un caso muy significativo fue el de Pamplona. Verboom ordenó elaborar proyectos a prestigiosos ingenieros como Alejandro de Rez e Ignacio Sala. (Cfr. ECHARRI IRIBARREN, 2000: 384-389). En 1725 se presentó personalmente en la ciudad y resolvió de manera magistral su proyecto general de 1726, mejorando notablemente los proyectos realizados por dichos ingenieros. Cfr. ECHARRI IRIBARREN, 2000: 418-431. 
conocimiento personal in situ, el propio Verboom habría redactado su proyecto general. La segunda de las hipótesis consiste en suponer que los proyectos fueron posteriores, y que se debieron a cambios en la financiación o a otras circunstancias que obligarían a establecer una revisión de las brillantes propuestas del Ingeniero General. Cabría por último considerar que el proyecto de Juan Ballester y Zafra fuera anterior a la llegada de Verboom, y el de Diego Fabré fuera posterior. Procuraremos sin más hacer una descripción de las propuestas de estos ingenieros ante la imposibilidad de extraer conclusiones en firme por la ausencia de datos documentales que pudieran avalar alguna de estas hipótesis.

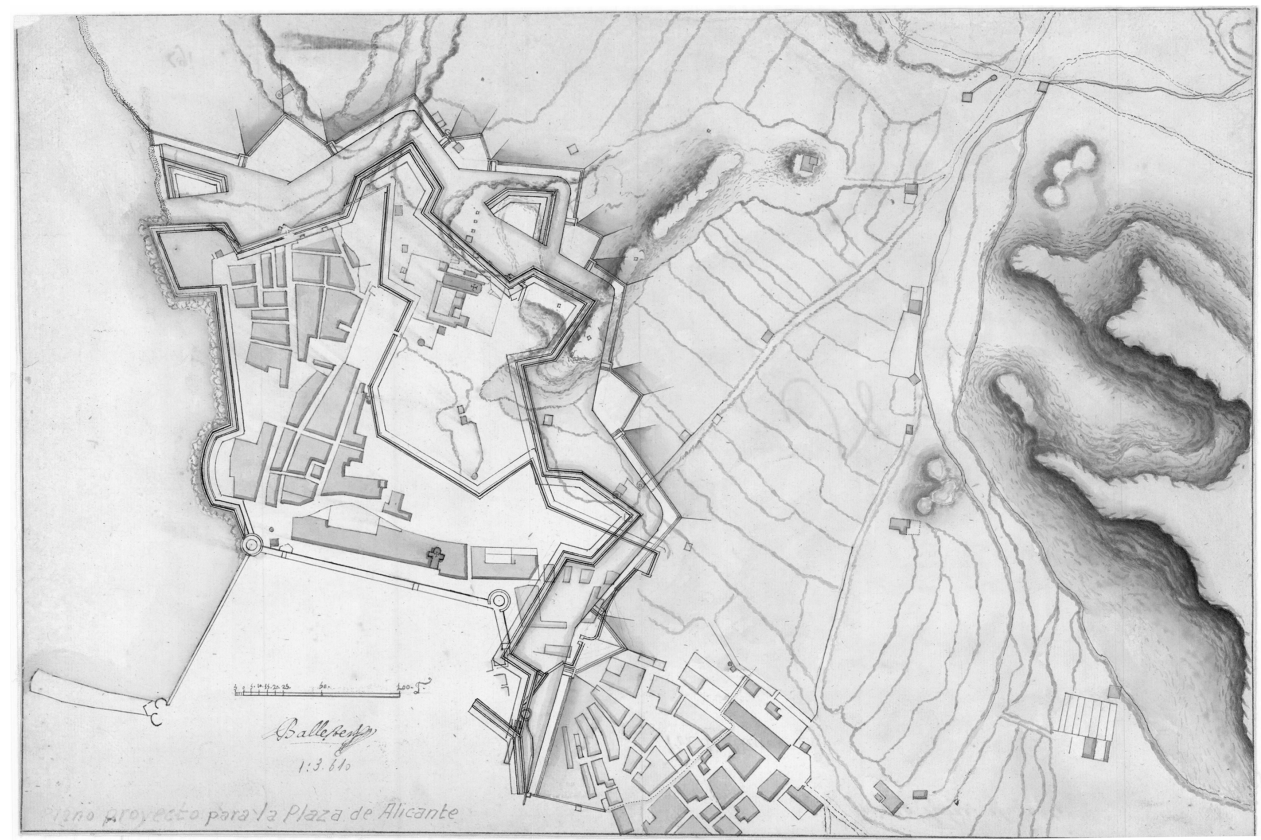

Fig. 3. «Plano y Proyecto para la Plaza de Alicante». Juan Ballester y Zafra. 1721. SGE. CARTOTECA HistóricA. AR G-T.3-C.3-296.

El ingeniero Juan Ballester y Zafra ${ }^{66}$ resolvía el nuevo cinturón amurallado con cinco baluartes de escala similar a la planteada por Verboom. Hay que destacar que delante del baluarte de San Carlos situaba una pieza de fortificación a modo de contraguardia, muy próxima al mar. De esta forma resolvía

66 Hijo del capitán Jaume Ballester i Soler, nació en Mahón en 1689. En sus años de juventud fue detenido en 1711 por su implicación en la conspiración "botifler". Ese mismo año 
mejor la defensa de la aproximación desde la playa de Babel. Sin embargo, presentaba algunos inconvenientes. Dejaba más desprotegida la cortina del frente, el flanco del baluarte derecho quedaba con un mal ángulo, y además sufriría sin duda con violencia las avenidas del barranco de San Blas.

En el frente bastionado dispuesto delante del convento de San Francisco, establecía un revellín, asimétrico, que era excesivamente grande y desproporcionado. Probablemente este defecto era fruto de su adaptación a la muntanyeta en que se asentaba. El relieve de la zona, como ya se ha señalado, dificultaba la disposición racional y simétrica del cinturón abaluartado para ser máximamente eficiente en su flanqueo cruzado. Pero todavía llama más la atención el frente contiguo, próximo a la puerta de la Huerta, ya que sus baluartes, excesivamente asimétricos y desproporcionados, hacían que la contraescarpa no tuviera sus caras paralelas a las caras de los bastiones, ni fueran fruto de la prolongación geométrica de la línea de tiro de las casamatas, o en su caso de las baterías de los flancos. Las deficiencias señaladas permiten decantarnos por la hipótesis de que fue elaborado con anterioridad al proyecto de Verboom, ya que no se entenderían de otra forma dichas deficiencias, ni se justificaría por qué modifica en cuestión de meses el revellín que el maestro e Ingeniero General había dispuesto en el frente del baluarte de San Carlos.

El segundo proyecto que cabe destacar se atribuye a Fernando Fabré67. Se describe en un plano de 1721 conservado en el SGE ${ }^{68}$. Se trata de una propuesta de seis baluartes y medio, pero esta vez sin revellines ni obras exteriores de fortificación. Llama la atención la desproporción existente en los baluartes del frente situado delante del convento de San Francisco, probablemente como consecuencia de querer amoldarse a la muntanyeta del mismo nombre. También se manifiestan los defectos de la excesiva estrechez del foso, y que la

salió de la isla de Menorca para incorporarse como cadete en las tropas filipistas. Se formó como ingeniero militar, ascendiendo a Ingeniero Ordinario en 1715, y participando en la construcción de la ciudadela de Barcelona. Acompañó a Verboom en las campañas de Sicilia en 1718. Fue nombrado Ingeniero Director en 1735, después de prestar servicios como Ingeniero en Segunda en Ceuta, Navarra y Orán, Director de las fortificaciones de Mallorca en 1740, y Mariscal de Campo en 1760, ocupando la Comandancia General de Mallorca de manera interina en el periodo 1761-1764. Es autor de numerosos proyectos y planos de fortificación, destacando las intervenciones en Orán (1726 a 1737), Ibiza y Mallorca (1738 a 1766), año en que falleció. Cfr. TOUS MELIÀ, 2009: 361. CAPEL et ALT., 1983: 57-59. TUR CATALÀ, 2008: 63-65.

67 Son escasas las noticias que tenemos de este ingeniero de origen francés. Sabemos que era Capitán de Ingenieros cuando realizó el proyecto. No se conserva ningún otro plano ni memoria de proyectos que hubiera desarrollado para otras plazas. Del hermano de ambos ingenieros, José, se conserva una amplia documentación. Llegaría a ser Ingeniero Jefe con grado de Coronel. Trabajó, entre otras, en las plazas de Gerona, Cádiz, puerto de Barcelona, Rosas y Hostalrich. Cfr. CAPEL et ALT., 1983: 166-68.

68 SGE. Cartoteca Histórica. Ar G-T.3-C.3-291. 
contraescarpa no es paralela a las caras de los bastiones. Estos defectos apuntados, al igual que en el proyecto de Ballester, nos inducen a concluir que debe tratarse de un proyecto anterior al de Verboom. El maestro se encargaría de corregir todas estas deficiencias.

El tercer y último proyecto tiene por autor al ingeniero Diego Fabré69, hermano de Fernando, sin duda con más oficio y experiencia que éste y Ballester en esa fecha. El cinturón proyectado no parece diferir mucho, a primera vista, del de sus predecesores. Contiene seis baluartes y un medio bastión, y sigue una disposición de conjunto bastante similar. Pero las diferencias son notables. Los bastiones tienen sus ángulos de flanqueo bien ajustados a las máximas de fortificación, así como la proporción entre la magnitud de la cortina y la dimensión de las caras de los baluartes. Delante de todas las cortinas establece revellines bien proporcionados. Los de los frentes extremos presentan una intencionada deformación en su geometría con el fin de poder batir mejor en el perímetro en los propios extremos. Una solución discutible, pero aplicada en otros proyectos similares de la época ${ }^{70}$. Esta disposición en sí misma hace el proyecto de Fabré mucho más ambicioso que los anteriores. Además añadía una contraguardia delante del revellín del convento de San Francisco, obra importante que retrasaría las aproximaciones del enemigo.

También destaca el correcto trazado del foso y la contraescarpa, paralelos a las caras de los bastiones y las caras de los revellines, con las plazas de armas, y los traveses o traversas dispuestas en el camino cubierto para evitar el temible tiro de rebote. Además, una gran singularidad de su proyecto es que establece la posibilidad de convertir el frente delante del convento da San Francisco en un hornabeque, con su revellín y contraguardia delante de los dos medios bastiones. Era una posibilidad interesante, pero que se encontraba con la dificultad de salvar las pendientes que generaba la muntanyeta de San Francisco.

En resumen, podemos valorar el proyecto de Diego Fabré como uno de los de mayor calidad técnica de la época. Aunque no llegaría a aprobarse para su ejecución, todo parece indicar que sirvió de base para Verboom a la hora de hacer la redacción de su propio proyecto. No parece probable que se tratara de un proyecto posterior al del Ingeniero General si consideramos que elevaba notablemente el coste de la obras. Es más que probable que Fabré trabajara por encargo de Verboom y que prepara el terreno de su visita a Alicante con un proyecto serio de fortificación. Y Verboom, una vez realizado el recono-

69 Tampoco abunda la documentación conservada de la labor de este ingeniero. Fue nombrado Ingeniero Ordinario el 3 de octubre de 1713. Además de sus trabajos en Alicante, realizó proyectos para la provisión de abastecimiento de agua en Puerto de Santa María en 1726, de los que se conservan dos planos. Cfr. CAPEL et ALT., 1983: 166.

70 CÁMARA MUÑOZ, 2005: 133-159. 
cimiento de la plaza y estudiado los diversos proyectos previos, en especial el de Fabré, habría optado por simplificar el cinturón abaluartado de este ingeniero y reforzar las baterías de costa, la plataforma de la Ereta, y el desvío del cauce del San Blas, sin el cual las obras de fortificación, y en concreto el baluarte de San Carlos, resultarían seriamente dañadas.

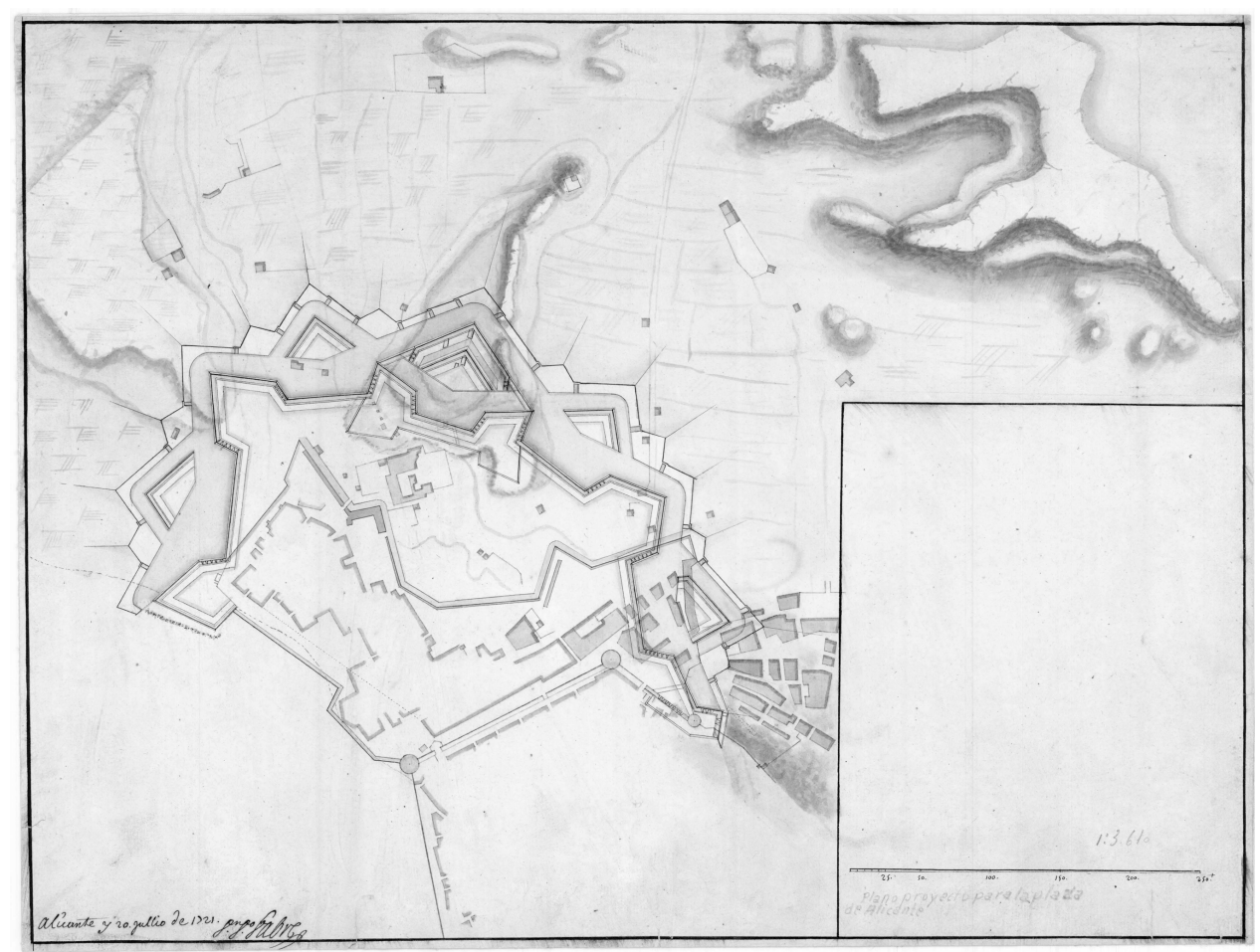

Fig. 4. «Plano y Proyecto Para la Plaza de Alicante». Diego Fabré. 20 de Julio de 1721. SGE. CARTOTECA HistóRICA. AR G-T.3-C.3-290.

\section{CONCLUSIONES}

El plano titulado «Plano de la Ciudad, Castillo y Puerto de Alicante y sus cercanías, con un Proyecto General para Fortificarla», conservado en el SGE, describe el proyecto elaborado por el Ingeniero General Jorge Próspero de Verboom en 1721 para poner Alicante en estado de defensa, tras las campañas sufridas durante la Guerra de Sucesión. Hasta el momento, el plano había sido publicado, pero no se había analizado, se desconocía su autor y la calidad 
técnica de las propuestas proyectadas, especialmente el proyecto de desvío del cauce del barranco de San Blas. Dicha propuesta era crucial para mantener operativo el puerto, impidiendo la deposición de sedimentos en las grandes avenidas de los meses de septiembre y octubre, y para preservar al baluarte de San Carlos y al nuevo cinturón abaluartado que debía construirse de los daños que producirían dichas aguas en sus lienzos y cimentaciones.

El proyecto de Verboom fue el más importante de cuantos se realizaron para Alicante a lo largo de su historia. Además fue uno de los primeros proyectos generales que elaboró el experto ingeniero tras su regreso de las campañas de Cerdeña y Sicilia en 1719. Alicante había sido una plaza estratégica por la fortaleza de su castillo y la importancia comercial de su puerto, y requirió por parte de la Secretaría de Guerra y su Ingeniero General mayores atenciones que Valencia, Denia o Cartagena. En efecto, durante el viaje que emprendería nuestro ingeniero por la costa mediterránea y plazas de la cornisa cantábrica, entre 1721 y 1726 , elaboró proyectos generales para un número reducido de plazas, entra las que destacan Alicante, Ceuta, el puerto de Málaga, Gibraltar, Pamplona, Fuenterrabía y San Sebastián. De entre estos proyectos, el de Alicante fue el primero que elaboró, y fue, junto con el de Pamplona, uno de los que mayores inversiones requerían. Fue sin duda un ambicioso y completísimo proyecto que nunca se llegaría a ejecutar, salvo el desvío del cauce del barranco de San Blas, absolutamente necesario para evitar que el puerto quedase inoperante.

\section{BIBLIOGRAFÍA}

Alberola, Armando, «La reconstrucción del Pantano de Tibi», Revista del Instituto de Estudios Alicantinos, 29, (Alicante, 1979): 65-91.

Bendicho, Vicente, Crónica de la muy ilustre, noble y leal ciudad de Alicante, Edición facsímil a cargo de Cabares, $\mathrm{M}^{\mathrm{a}}$ Luisa, de la de Bendicho, Vicente (1584-1642), Alicante, Ayuntamiento de Alicante, 1991.

Bevià i García, Màrius. «L'albacar musulmà del castell d'Alacant», Sharq Al-Andalus, 1, (Alicante, 1984): 131-140.

Bragard, Philippe, Dictionnaire biographique des ingénieurs des fortifications: PaysBas espagnols, principauté de Liège, Franche-Comté, 1504-1713, Namur : Amis de la Citadelle de Namur, 2011.

Cámara Muñoz, Alicia, «Murallas para la guerra y para la paz. Imágenes de la ciudad en la España del siglo XVI», Espacio, Tiempo y Forma, Serie VII, $\mathrm{H}^{\mathrm{a}}$ del Arte, t. 6, 1993: 149-174.

Cámara Muñoz, Alicia, «La arquitectura militar del padre Tosca y la formación teórica de los ingenieros entre austrias y borbones», en Cámara Muñoz, Alicia 
(coord.), Los ingenieros militares de la Monarquía Hispánica en los siglos XVI y XVII, Madrid, Ministerio de Defensa, 2005; 133-159.

Cámara Muñoz, Alicia, «Les fortifications de la monarchie espagnole. Un système basé sur l'experience», en Warmoes, Isabelle. Vauban, bâtisseur du Roi-Soleil, París, Somogy éditions d'art, 2007; 48-54.

Camarero Casas, E., Bevià i García, M, Bevià i García, J.F. Tibi un pantano singular, Valencia, Generalitat, Conselleria d'Obres Públiques, 1989.

Capel, Horacio, et Alt., Los ingenieros militares en España, siglo XVIII. Repertorio bibliográfico e inventario de su labor científica y espacial, Barcelona: Ediciones y Publicaciones de la Universidad de Barcelona (Colección "Geocrítica. Textos de Apoyo"), 1983.

Capel, Horacio, Sánchez, Joan Eugeni y Moncada, Omar, De Palas a Minerva. La formación científica y la estructura institucional de los ingenieros militares en el siglo XVIII, Madrid, Barcelona, CSIC, Serbal, 1988.

Capel, Horacio, «Los ingenieros militares y el sistema de fortificación en el siglo XVIII», en Cámara Muñoz, Alicia (coord.), Los ingenieros militares de la Monarquía Hispánica en los siglos XVI y XVII, Madrid, Ministerio de Defensa, 2005; 231-67.

Carrillo de Albornoz y Galbeño, Juan, «El Ingeniero General Don Jorge Próspero de Verboom, un Militar Ilustrado», en Milicia y sociedad ilustrada en España y América (1750-1800), Actas de la Jornadas Nacionales de Historia Militar, vol. 2, Sevilla, Deimos, 2003; 315-334.

Chafrion, Ioseph, Escuela de Palas o sea Curso Mathematico dividido en XI tratados, que contienen la Arithmetica, Geometria Speculativa... y ultimamente el Arte Militar, Milan, Emprenta Real, por Marcos Antonio Pandulpho Malatesta, 1693.

Cobos, Fernando, «La fortificación española en los siglos XVII y XVIII: Vauban sin Vauban y contra Vauban», en Silva Suárez, M. (ed.), Técnica e ingeniería en España. El siglo de las luces, Vol. II, Madrid, Real Academia de Ingeniería, Institución «Fernando el Católico», Zaragoza, Prensas Universitarias de Zaragoza, 2005; 469-520.

Cobos Guerra, Fernando, Castro Fernández, José Javier, «Los ingenieros, las experiencias y los escenarios de la arquitectura militar española en el siglo XVII», en Cámara Muñoz, Alicia (coord.), Los ingenieros militares de la Monarquía Hispánica en los siglos XVI y XVII, Madrid, Ministerio de Defensa, 2005; 71-95.

De Groof, Bart; Bertini, Giuseppe, «Francesco de Marchi y la monarquía española», en Hernando Sánchez, Carlos José (coord.), Las Fortificaciones de Carlos V, Madrid, Ministerio de Defensa; Asociación Española de Amigos de los Castillos; Sociedad Estatal para la Conmemoración de los Centenarios de Felipe II y Carlos V, DL, 2000; 389-411.

Echarri Iribarren, Víctor, Las Murallas y la Ciudadela de Pamplona, Pamplona, Departamento de Educación y Cultura-Institución Príncipe de Viana, Gobierno de Navarra, 2000. 
Echarri Iribarren, Víctor, «El desvío del cauce del barranco de San Blas en Alicante: proyectos realizados desde 1721 hasta 1787», Biblio 3W. Revista bibliográfica de Geografía y Ciencias Sociales, [en línea] 16/954 (2011). Disponible en: http://www.ub.es/geocrit/b3w-954.htm.

Echarri Iribarren, Víctor, «La verdadera autoría y fecha del plano de Alicante atribuido a Juan Bautista Paravesino y fechado en 1656», Tiempos Modernos, Revista de Historia Moderna [en línea] 7/23, (2011). Disponible en: http://www. tiemposmodernos.org/tm3/index.php/tm/article/view/255/316.

Espino López, Antonio, Guerra, fisco y fueros. La defensa de la Corona de Aragón en tiempos de Carlos II, 1665-1700, Valencia, Publicacions de la Universitat de València, 2007.

Fernández de Medrano, Sebastián, El arquitecto perfecto en el Arte Militar: Dividido en cinco libros. El $1^{\circ}$ contiene la fortificación regular e Irregular a la Moderna..., Bruselas, Casa de Lamberto Marchant, 1700.

Galland Seguela, Martine, Les Ingénieurs Militaires Espagnols de 1710 à 1803, Madrid, Bibliothèque de la Casa de Velázquez, vol. 40, 2008.

Giménez López, Enrique, Alicante en el sigo XVIII. Economía de una ciudad portuaria en el antiguo régimen, Valencia, Institución Alfonso el Magnánimo, 1981.

González Avilés, Ángel Benigno, «El origen del muelle de Alicante: el proyecto de Antonelli», Revista de Obras Públicas, 3.532 (Madrid, 2012): 49-58.

González Avilés, Ángel Benigno, «Mejoras en las fortificaciones abaluartadas de Alicante durante la Guerra de Sucesión», Tiempos Modernos, Revista de Historia Moderna [en línea] 7/25, (2012). Disponible en: http://www.tiemposmodernos. org/tm3/index.php/tm/article/view/289/366.

Gutiérrez, Ramón y Esteras, Cristina, Territorio y Fortificación. Vauban, Fernández de Medrano, Ignacio Sala y Félix Prósperi, influencia en España y América, Madrid, Ediciones Tuero, S.A., 1991.

Llave y García, Joaquín de la, «Don Jorge Próspero de Verboom. Marqués de Verboom», Memorial de Ingenieros, 28 (Madrid, 1911): 109-160.

Maltés, Juan Bautista y López, P. Lorenzo, Ílice Ilustrada: Historia de la muy noble, leal y fidelísima ciudad de Alicante, que escribió..., Edición facsímil del manuscrito conservado en el AMA, de 1752, Alicante, Ayuntamiento de Alicante, 1907.

Montojo Montojo, Vicente, «El comercio de Alicante a mitad del siglo XVII según los derechos y sisas locales de 1658-1662 y su predominio sobre el de Cartagena», Murgetana, 122 (Murcia, 2010): 43-66.

Montojo Montojo, Vicente, «El comercio de Alicante en el reinado de Carlos II», Saitabi: revista de la Facultad de Geografia i Història, 60-61 (Valencia, 20102011): 327-345.

Muñoz Corbalán, Juan Miguel, Los Ingenieros Militares de Flandes a España (16911718). 2 Tomos, Madrid, Centro de Publicaciones del Ministerio de Defensa, 1993.

Orts Y Bosch, Pere María. Alicante, notas históricas (1373-1800). Valencia, 1971. 
Roselló Verger, Vicenç M., Cartografia Històrica dels Països Catalans, Valencia, Publicacions de la Universitat de València i Institut d'Estudis Catalans, 2008.

Rosenau, Helen, La ciudad ideal. Su evolución arquitectónica en Europa, Madrid, Alianza, 1986.

Rosser Limiñana, Pablo, Origen y Evolución de las Murallas de Alicante, Alicante, Ayuntamiento de Alicante. Conselleria de Cultura, Educació i Ciencia. Generalitat Valenciana, 1990.

Tous Melià, Juan, Palma a través de la cartografia (1596-1902), Palma, Ayuntamiento de Palma, 2009.

Tur Català, Margalida (coord.), Fills il $\cdot$ lustres de Palma, Palma, Promomallorca, D.L., 2008.

Vauban, Sébastien Le Prestre, Veritable Manière de Fortifier de Mr. de Vauban. Où l'on voit de quelle méthode on se sert aujourd'hui en France..., Amsterdam, Chez Pierre Mortier, Paris, 1689.

Vauban, Sébastien Le Prestre, Traité des Siéges sur L'attaque et La Defense des Places de Guerre Par Monsieur De Vauban..., La Haya, Chez Pierre de Hondt, 1737.

Viganò, Marino, «El fratin mi ynginiero». I Paleari Fratino da Morcote ingegneri militari ticinesi in Spagna (XVI-XVII secolo), Bellinzona, Edizioni Casagrande, 2004.

Warmoes, Isabelle, «Vauban et l'art de la fortification», en Warmoes, Isabelle. Vauban, bâtisseur du Roi-Soleil. Catálogo de la exposición organizada por la Cité de l'architecture et du patrimoine, Paris, del 14 de noviembre de 2007 al 5 de febrero de 2008, París, Somogy éditions d'art, 2007; 190-197.

Wawermans, Henri, El Marqués de Verboom, ingeniero militar flamenco al servicio de España, Traducido del francés y adicionado con notas recogidas por el difunto coronel de ingenieros D. Mariano Bosch y Arroyo, por el coronel Graduado D. Joaquin de la Llave y García, Madrid, Imprenta de Memorial de Ingenieros, 1894.

Recibido: 30/04/2012

Aceptado: 04/02/2013 